\title{
Nutrient digestibility, organ morphometry and performance in vaccinated or non- vaccinated Lawsonia intracellularis infected piglets
}

Christian Visscher ${ }^{1 *}$ D, Jasmin Mischok ${ }^{1}$, Saara Sander ${ }^{1}$, Marion Schmicke ${ }^{2}$, Eva-Ursula Peitzmeier ${ }^{3}$, Isabel von dem Busche ${ }^{3}$, Karl Rohn $^{4}$ and Josef Kamphues ${ }^{1}$

\begin{abstract}
Background: Lawsonia intracellularis is one of the world's most important infectious diseases in pork production with regard to economic losses. So far, studies are missing that describe the effects of a natural infection of piglets on the digestibility of nutrients, possible effects on performance and the morphometrics of the intestine depending on whether piglets are vaccinated, clinically healthy or clinically affected with regard to Lawsonia intracellularis induced diarrhoea.

Results: Digestibility studies were performed on a total of 27 eight-week-old piglets with naturally occurring Lawsonia intracellularis infection in a trial with three repetitions. Nine out of 27 animals were vaccinated as suckling pigs with a commercial Lawsonia intracellularis vaccine (vac; Enterisolølleitis). Half of the remaining 18 animals were without clinical signs of infection (non-vac/cs-), half showed moderate clinical signs of Lawsonia intracellularis induced diarrhoea (non$\mathrm{vac} / \mathrm{cs}+$ ). All three groups were fed one identical complete diet ad libitum. Faecal shedding of Lawsonia intracellularis was found in all groups (25 out of 27 animals). Numerically, the mean excretion in the group non-vac/cs + (7.69 \pm 1.65 $\log _{10}$ copies/ $\mathrm{g}$ faeces) was higher in comparison to the group non-vac/cs- (5.83 $\pm 2.35 \log _{10}$ copies/ $\mathrm{g}$ faeces) and vaccinated animals (vac: $6.00 \pm 2.89 \log _{10}$ copies/ $\mathrm{g}$ faeces). The average daily weight gain (ADG; $\varnothing 8.66$ day period) differed significantly (vac: $894^{\mathrm{a}} \pm 73.3$, non-vac/cs-: $87^{\mathrm{ab}} \pm 86.3$, non-vac/cs+: $785^{\mathrm{b}} \pm 137 \mathrm{~g} /$ day). The apparent total tract digestibility (ATTD) of nitrogen was significantly lower in clinically affected animals (vac: $83.0^{\text {a }} \pm 1.72$, non-vac/cs-: $83.9^{\mathrm{a}} \pm 2.03$, non-vac/cs+: $\left.80.7^{\mathrm{b}} \pm 2.57\right)$. The total length of the small intestine in clinically affected animals increased significantly (vac: $15.9^{\mathrm{ab}} \pm 1.57$, non-vac/cs-: $14.6^{\mathrm{b}} \pm 1.12$, non-vac/cs+: $16.2^{\mathrm{a}} \pm 1.37 \mathrm{~m}$ ). The relative body weight depending on the length of the small intestine was lower for clinically affected animals (vac: $1.72^{\mathrm{a}} \pm 0.21$, non-vac/cs-: $1.83^{\mathrm{a}} \pm 0.17$, non-vac/cs+: $1.56^{\mathrm{b}} \pm 0.12 \mathrm{~kg} / \mathrm{m}$ ).
\end{abstract}

Conclusion: These studies show that clinically moderate L. intracellularis infections lead to significantly lower ADGs in comparison to vaccinated animals. The disease is also found in altered intestinal morphometry and reduced total $\mathrm{N}$ digestibility if clinical signs occur.

Keywords: Lawsonia intracellularis infection, Vaccination, Digestibility, Performance, IGF-1, Organ morphometrics

\footnotetext{
* Correspondence: Christian.Visscher@tiho-hannover.de

${ }^{1}$ Institute for Animal Nutrition, University of Veterinary Medicine Hannover,

Foundation, Bischofsholer Damm 15, D-30173 Hannover, Germany

Full list of author information is available at the end of the article
}

(c) The Author(s). 2018 Open Access This article is distributed under the terms of the Creative Commons Attribution 4.0 International License (http://creativecommons.org/licenses/by/4.0/), which permits unrestricted use, distribution, and reproduction in any medium, provided you give appropriate credit to the original author(s) and the source, provide a link to the Creative Commons license, and indicate if changes were made. The Creative Commons Public Domain Dedication waiver (http://creativecommons.org/publicdomain/zero/1.0/) applies to the data made available in this article, unless otherwise stated. 


\section{Background}

Infections with Lawsonia intracellularis (L. intracellularis) in pigs lead to economic losses both in the case of clinical manifestations and subclinical infections [1-4]. Lower performance results from reduced growth and an impaired feed efficacy [5-8]. The overall prolonged rearing and fattening period is a typical finding of subclinical infections [1, 9-11]. This is a common sign of an $L$. intracellularis infection in practice [2]. Clinically apparent infections are traditionally associated with diarrhoea and can be related to animal losses due to the haemorrhagic course named porcine haemorrhagic enteropathy $[4,12]$. These may occur more frequently in individual stocks, but play a less important role overall [13].

In order to convert the absorbed nutrients at their highest rate into weight gain, a good state of health of the growing animals is essential. This excludes any avoidable activation of an inflammatory immune response, which might also be common for gastrointestinal infections [14]. High concentrations of proinflammatory cytokines often lead to a condition known as the systemic inflammatory response syndrome (SIRS) [15] which is often related to sickness symptoms like decreased feed and water intake $[15,16]$. The reduced appetite is mediated by these aforementioned cytokines acting in the central nervous system [15-17]. There are findings indicating that Insulin-like growth factor 1 (IGF-1) is potent in attenuating sickness behaviour induced by tumour necrosis factor-alpha [17]. On the other hand there are indications that the immune response is hardly activated in the initial course of an infection with $L$. intracellularis [18].

In general, an immediate reduction in average daily feed intake (ADFI) for pigs affected by digestive bacterial infections can be estimated at 15\% [19]. Nonetheless, also an impaired digestibility of the nutrients has to be considered in cases of an $L$. intracellularis infection. With regard to the pathomorphological changes in the intestines of infected pigs, it has to be assumed that due to the reduced permeability of the intestinal wall there is a reduced absorption of certain nutrients in cases of an L. intracellularis infection [20, 21]. For infections with porcine epidemic diarrhoea virus apparent total tract digestibility (ATTD) of dry matter (DM) and energy are decreased by 8 and 12\%, respectively [22]. However, the digestibility of nutrients and the concentrations of nutrients in the digesta of the terminal ileum influence the length of the gastrointestinal tract [23]. This is particularly noticeable after weaning because here very fast adaptation can be seen in the form of elongation [23]. In general, the response of the gastrointestinal tract to ingestion of nutrients is a complex and closely controlled process [24]. Mechanical and chemical control mechanisms are involved in the short and long term. Due to the feed consumption there is a distension of hollow viscera along with activation of both elongation and tension mechanoreceptors [24]. There are simultaneously nutrient-sensing chemoreceptors in the upper gastrointestinal tract [24]. These are involved in detecting the presence of all main categories of nutrients in the lumen [24]. A leading mechanism of intestinal adaption to enteral nutrients is driven by humural factors like the intestinotrophic peptide glucagon-like peptide-2 (GLP-2) [25, 26]. Enteroendocrine L-cells secrete GLP-2 after direct stimulation by nutrients distally in the small intestine [25].

To date, no investigation has been carried out on how an infection with $L$. intracellularis might affect the digestibility of nutrients, performance, IGF-1 status and gastrointestinal tract morphometry as a result of natural exposure when non-vaccinated and vaccinated animals are compared.

\section{Methods}

Animal experiments were carried out according to German regulations. It was not an animal experiment requiring a notification or an approval according to the Animal Protection Act ( $\$ 7$, paragraph 2, sentence 3). Interventions before dissection were not carried out. The animals were killed according to $\$ 4$, paragraph 3 of the Animal Protection Act, exclusively to use their organs or tissues for scientific purposes.

\section{Origin of animals, preparation and selection}

All animals used in these trials came from one farm with 420 sows of Danish genetics (DK: Danish Landrace 50\% $\mathrm{x}$ Yorkshire 50\%). In total, 27 piglets (DK x Pietrain) were used in a trial with three repetitions. The sows in the herd were regularly vaccinated (Porcine Reproductive and Respiratory Syndrome Virus, Swine Influenza Virus, Porcine Parvovirus, Erysipelothrix rhusiopathiae, Escherichia coli + Clostridium perfringens dam vaccine) as were the piglets (Porcine Circovirus 2, Mycoplasma hyopneumoniae and Haemophilus parasuis). In the context of regular and long-term screening programmes, the herd showed no signs of Salmonella and Brachyspira infections. Clinical symptoms of an $L$. intracellularis infection (confirmed by pathogen detection in faeces) were, on the other hand, a common finding in piglets at an age of seven to nine weeks. Before the starting the experimental trials, additional results of serological analyses of piglets were obtained from the veterinarian of the herd. From these random tests in the rearing phase of piglets, it was found that there were no serological positive animals in the middle of this phase whereas at the end of the rearing phase, only $10 \%$ were still serological negative (data not shown).

The production system on the farm was organised in a two-week rhythm. During the trial period every two weeks approximately 50 piglets from a total of four to 
five complete litters were vaccinated with a commercial $L$. intracellularis vaccine (Enterisol Ileitis, Boehringer Ingelheim Vetmedica GmbH, Ingelheim / Rhine, Germany) on the 21st day of life. The vaccination was done via oral drenching. Subsequently, the piglets were marked individually.

At weaning all 450 to 500 piglets in a group were placed in a piglet rearing compartment in groups of 12 to about 30 animals on fully slatted floors (Fig. 1). Non-vaccinated and vaccinated animals were mixed. From weaning to the presumed initial $L$. intracellularis infection time point, samples from the individual stables were tested for their $L$. intracellularis status by real-time PCR using established methods [27]. With the positive proof a change to a single-animal examination procedure took place. All piglets in a weaning group were clinically examined. Individual samples were collected from conspicuous animals with regard to faecal quality (healthy pigs with moderate to soft feaces consistency) and analysed by means of real-time PCR [27]. After obtaining the results, three conspicuous animals (no siblings) were taken from the appropriate weaning group (non-vac/cs+). At the same time three clinically healthy ones (non-vac/cs-) and three vaccinated animals (vac+) of the same age and identical weight were chosen from the group, if possible in a balanced gender relationship. All selected animals were transported to the Institute for Animal Nutrition, University of Veterinary Medicine Hannover, Foundation, Hannover, Germany.

\section{Animal husbandry and experimental conditions}

The pigs were housed individually in $3 \times 1 \mathrm{~m}$ boxes during the entire trial period. The boxes were equipped with a nipple drinker, a $1 \mathrm{~m}$ long earthenware trough at one of the narrow sides of the box, an infrared warming lamp and (manipulable material). Visual contact to other animals was possible at all times. The boxes had a concrete floor. All three repetitions of the trial were performed identically.

\section{Diet and digestibility trials}

The pigs continued to receive the diet they were accustomed to on the farm. The diet contained $41.0 \%$ wheat, $35.0 \%$ barley, $18.0 \%$ soybean meal, $2.00 \%$ soybean oil and $4.00 \%$ of a mineral and vitamin supplement (MOVIKALIN Speed $10^{\circ}$, HS-Kraftfutterwerk, Ochtrup, Germany; Table 1).

The nutrient composition was in accordance with the official recommendation for piglets in Germany. The complete diet for all trial repetitions derived from one batch. The digestibility trial consisted of two phases starting with a 3-day adaptation period followed by a five-day collection period. The adaptation period was shortened to only three days due to the use of the identical diet already on the farm. In this way, the experiment still focused on the clinically conspicuous phase of the natural L. intracellularis infection. Chromium oxide $(0.5 \%)$ was added to the diet as a marker for calculating the precaecal digestibility. The diet was offered ad libitum. The feed was changed once a day. Feed refusals were removed and the amount determined after drying at $103{ }^{\circ} \mathrm{C}$. The collected faeces were weighed by means of electronic scales (Acculab, Sartorius AG, Göttingen, Germany) and then frozen. At the end of the collection period, an aliquot of the total amount of faeces was collected after thawing and homogenisation for further analysis.

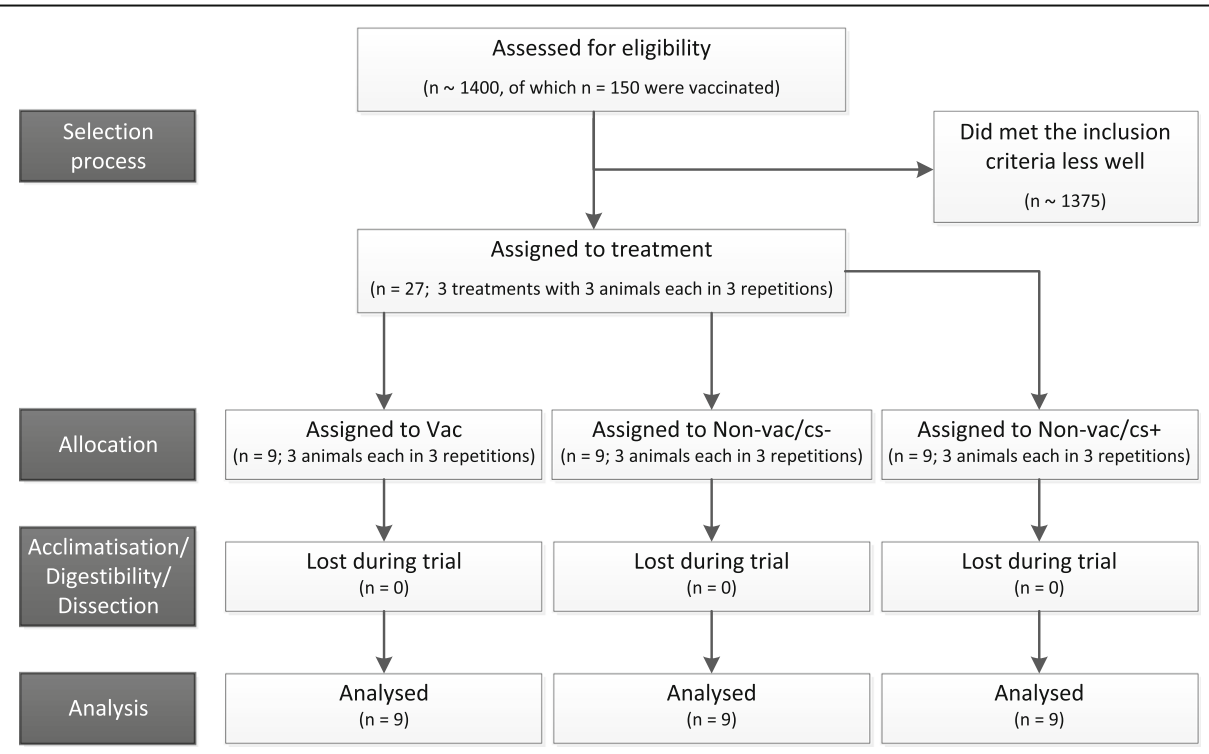

Fig. 1 Clinical trial flow diagram. The diagram indicates selection process and loss of animals during the trial 
Table 1 Energy content and concentrations of ingredients in the diet for rearing piglets

\begin{tabular}{lll}
\hline Item & & Content \\
\hline Metabolisable Energy (ME, MJ) & per kg diet & 13.8 \\
Crude ash & g/kg DM & 56.7 \\
Crude fat & 38.4 \\
Crude fibre & 26.9 \\
Crude protein & 201 \\
Starch & 480 \\
Sugar & \\
Lysin & 21.6 \\
Ca & 16.5 \\
P & 9.88 \\
Na & mg/kg DM & 6.38 \\
Cu & \\
Zn & & 156 \\
Se & & 150 \\
\hline
\end{tabular}

Mineral and Vitamin supplement (4\% of complete diet) contained 500,000 I.E Vit A, 50000 I.E. Vit. D3, 3000 mg Vit. E, $30 \mathrm{mg}$ Jodine

\section{Dissection}

At day of the dissection the pigs were fed in a timely manner. There was an interval of nine hours between offering the fresh diet and death of each animal. In each repetition 3 out of 9 animals were dissected on the day of finishing the digestibility trial, the remaining animals on the following day. Prior to the dissection the animals were anaesthetised with neuroleptanalgesia by means of a combination of ketamine (Ursotamin 10\%, Serumwerke Bernburg, Bernburg, Germany; active ingredient: ketamine hydrochloride, dosage: $15 \mathrm{mg} / \mathrm{kg}$ body weight intramuscularly) and azaperone (Stresnil 4\% Janssen Animal Health, Neuss, Germany; active ingredient: azaperone, dosage: $2 \mathrm{mg} / \mathrm{kg}$ body weight intramuscularly). In the course of the dissection a blood sample was taken intracardially from the pigs. After that, pigs were euthanised with T6 $1^{\circ}$ intracardially (Intervet, Unterschleißheim, Germany; active ingredients: tetracaine hydrochloride, embutramide, mebenzonium iodide, dosage: $0.6 \mathrm{~mL} / 10 \mathrm{~kg}$ body weight).

Before opening the abdominal cavity the naso-rump length of the animals was measured. The abdominal cavity was opened along the linea alba as well as a relief cut being performed in the flank region. The caecum was pre-placed, double-ligated and then removed. Other ligatures were placed directly between the pylorus and the jejunum and in front of the rectum. The removal of the stomach was done by dull preparation of the diaphragm and connective tissue. After placing an intestinal clamp on the cardia and severing the connection to the jejunum, the stomach was removed. Subsequently, the removal of the whole intestinal tract and the application of a ligature between the colon and the jejunum took place.
Both the colon and the jejunum were freed from the mesenterium and their total length was measured in the filled state, also the length of the blind arm was measured. Digesta from the terminal small intestine for precaecal digestibility determination was taken in accordance with common procedures [22]. The contents of the different segments (stomach, small intestine, caecum, colon) were collected separately in plastic containers and used for further analysis.

\section{Analytical methods}

Diets were analysed by standard procedures in accordance with the official methods of the VDLUFA [28].The analyses were always performed in duplicate. The dry matter content was determined by drying to the weight constancy at $103{ }^{\circ} \mathrm{C}$. The crude ash was analysed by means of incineration in the muffle furnace at $600{ }^{\circ} \mathrm{C}$ for $6 \mathrm{~h}$. The total nitrogen content was determined by means of the analyser Vario Max (Elementar, Hanau, Germany), which operates according to the principle of a catalytic tube combustion (DUMAS combustion method). The molecular nitrogen formed by reduction from nitric oxide was detected by a thermal conductivity detector and the nitrogen content was calculated by the device software. The crude protein content of the sample was calculated by multiplication with a constant factor of 6.25. The crude fat content was determined after acid hydrolysis in the Soxhlet apparatus. The content of crude fibre was determined after washing in diluted acids and alkalis by established methods. The determination of starch contents was carried out polarimetrically (Polatronic E, Schmidt und Haensch GmbH \& Co., Berlin, Germany). The sugar content was analysed according to Luff-Schoorl by titration with sodium thiosulphate. The mineral content was determined in accordance with the official methods [28] by atomic absorption spectrometry (Unicam Solaar 116, Thermo, Dreieich, Germany). The analyses of the chyme were performed in principle by the identical methods as described for feeds.

The determination of mean $L$. intracellularis genome equivalents (GE) was done from the aliquot of the homogenised faeces via quantitative PCR according to established methods [29]. The numbers are shown in the logarithm of 10 .

Insulin-like growth factor I (IGF-1) concentration was determined using a commercial radioimmunoassay acoording to the standard operation manual (A15729, IRMA IGF-I; Beckman Coulter, CA, USA). The assay was validated for porcine plasma by determining the recovery and an intra-assay coefficient of variation by measuring 20 times one sample within one test routine. The recovery was $94,5 \%$ and the intra-assay was $6,3 \%$. 


\section{Statistical analyses}

Normal distribution of the model residuals was confirmed by Kolmogorov-Smirnov-Test and visual assessment of q-q - plots. All data were included into a descriptive analysis with calculation of the arithmetic mean, standard deviation, minimum and maximum.

The influence of the factor group (vac, non-vac/cs-, non-vac/cs+) on the quantitative variables (Log10 genome equivalents; DM faeces, performance parameters, digestibility nutrients, organ morphometry parameters) was carried out by a one way variance analysis of variance (ANOVA) with REGWQ (Ryan-Einot-Gabriel-Welsch multiple Range-Test) post hoc test for multiple pairwise comparisons, concerning the experimentwise errorrate.

Analyses were carried out with the statistical software SAS, version 9.3 (SAS Institute, Cary, NC, USA), using SAS $^{\circ}$ Enterprise Guide 5.1. Differences were taken to be statistically significant when $P<0.05$.

\section{Results}

The investigations were carried out on a total of 27 piglets. In all three repetitions of the trial, the general health status of each animal was checked at least twice a day. The 27 animals showed an undisturbed general state. Moderate clinical diarrhoea in all animals of the non-vaccinated, clinically affected group (non-vac/cs+) previously found on the farm was included in the study as a selection criteria (moderate diarrhoea induced by $L$. intracellularis).

\section{Lawsonia intracellularis excretion and performance}

Faecal shedding of $L$. intracellularis was found in all groups (25 out of 27 animals). There were no statistically significant differences in the absolute level of pathogen excretion (Table 2). Numerically, the mean excretion in the groups non-vac/cs- and vac was lower $(-1.87$ or

Table 2 Overview on Lawsonia intracellularis excretion, dry matter content of faeces and growth performance

\begin{tabular}{|c|c|c|c|c|c|c|}
\hline \multirow[t]{2}{*}{ Item } & \multicolumn{2}{|l|}{ Vac } & \multicolumn{2}{|c|}{ Non-vac/cs- } & \multicolumn{2}{|c|}{ Non-vac/cs+ } \\
\hline & Mean & SD & Mean & SD & Mean & SD \\
\hline $\log _{10}$ genome equivalents & 6.00 & 2.89 & 5.83 & 2.35 & 7.69 & 1.65 \\
\hline DM faeces (g/kg DM) & $23.6^{\mathrm{a}}$ & 1.84 & $24.5^{\mathrm{a}}$ & 1.68 & $21.1^{\mathrm{b}}$ & 1.98 \\
\hline BW start (kg) & 19.2 & 1.64 & 19.2 & 1.36 & 18.4 & 1.53 \\
\hline BW Dissection $(\mathrm{kg})^{\mathrm{C}}$ & 27.0 & 1.71 & 26.7 & 2.19 & 25.3 & 2.43 \\
\hline ADFI (kg DM/day) $)^{d}$ & 1.297 & 0.116 & 1.207 & 0.119 & 1.165 & 0.148 \\
\hline ADG (kg/day) & $0.894^{\mathrm{a}}$ & 0.073 & $0.857^{\mathrm{ab}}$ & 0.086 & $0.785^{b}$ & 0.137 \\
\hline FCR (kg diet/kg ADG) & 1.410 & 0.075 & 1.422 & 0.078 & 1.470 & 0.061 \\
\hline
\end{tabular}

Vac vaccinated with Enterisol Illeitis, Non-vac/cs- not vaccinated, clinically no signs, Non-vac/cs + not vaccinated, clinical signs

a,b Values within a row with different superscripts differ significantly at $P<0.05$ 'Dissection was done in 3 out of 9 animals 8 days after starting experiment, in 6 out of 9 piglets 9 days after start of experiment

dDue to technical detection problems, three values are missing from one of three repetitions rather $-1.70 \log$ units/g faeces). The clinically affected animals showed at the same time significantly lower faecal dry matter compared to the other two groups ($10.6 \%$ compared to vac and $-13.9 \%$ compared to the group non-vac/cs-). Neither at the trial's start nor at the time of the dissection did the body masses differ between the three groups. The daily feed intake did not differ significantly between groups. Numerically, differences between the groups could be seen. The feed intake in the group non-vac/cs + was reduced by $10.2 \%$ and in group non-vac/cs- by $6.94 \%$ compared to the feed intake of vaccinated animals. However, the sample size included only 2 out of 3 trials. The average daily body weight gains (ADG) were significantly different between the clinically affected (non-vac/cs+) and the vaccinated group (vac). In the former, the growth was reduced by $12.2 \%$. The non-vaccinated, clinically healthy animals showed no significant differences in average daily gains compared to one of the other groups. These were only $4.14 \%$ lower than for the group vac. The FCR did not differ between the groups.

In the animals' blood at the time of dissection the concentrations of IGF-1 were measured (Fig. 2). There were no significant differences in the IGF-1 levels between the three groups (Mean $\pm \mathrm{SD}$ in $\mathrm{ng} / \mathrm{mL}$; vac: $285 \pm 68.3$; non-vac/cs-: $272 \pm 57.1$; non-vac/cs+: $226 \pm 74.4$ ).

\section{Digestibility of nutrients}

There were no differences between the groups in regard to the precaecal digestibility of nutrients (Table 3).

The ATTD of the nutrients differed significantly only with respect to the crude protein (Table 4). The group with clinically affected animals showed a significantly lower N-digestibility $(-2.77 \%$ compared to group vac; $3.81 \%$ compared to non-vac/cs-). The digestibility of organic matter, raw fat, crude fibre and starch did not differ significantly.

\section{Morphometry of organs}

The total length of the small intestine in clinically conspicuous animals was significantly longer $(+1.60 \mathrm{~m}$ against group non-vac/cs-; Table 5). In relation to the nose-rump length, the body mass was significantly higher in vaccinated animals $(+7.8 \%$ per $\mathrm{m})$. That means, it is concentrated more mass per unit of length. Also, the clinically inconspicuous animals had a significantly higher body mass per $\mathrm{m}$ length of the small intestine $(+17.3 \%$ per $\mathrm{m}$ ) in relation to clinically conspicuous animals.

The vaccinated animals had the highest ADG (+ 15.4\% per $\mathrm{m}$ ) in proportion to the nose-rump length. Therefore, per unit body length more gain in body mass is concentrated. The vaccinated and also the clinically inconspicuous animals each had the highest ADG in 


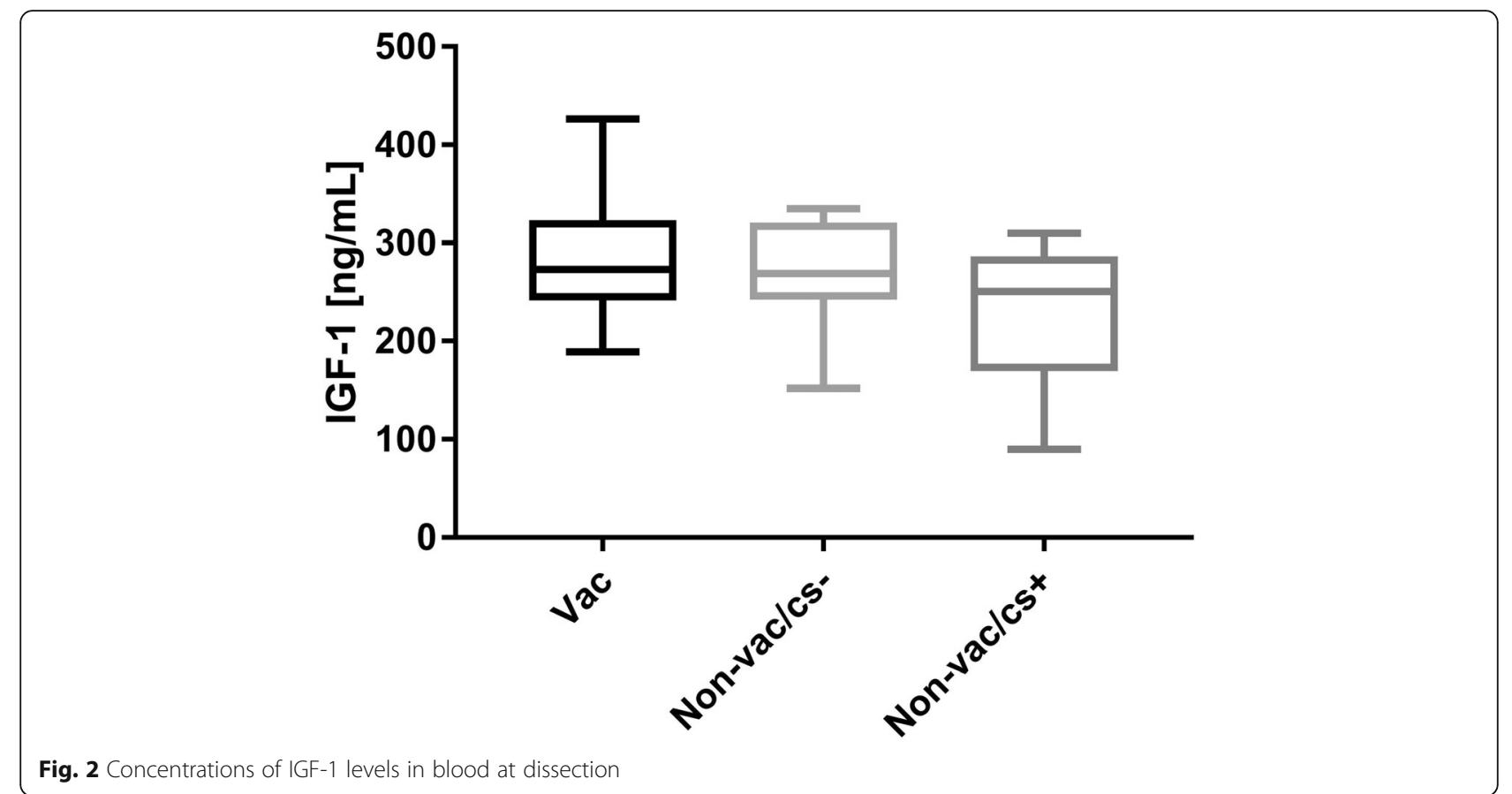

relation to the length of the small intestine $(+18.2 \%$ per $\mathrm{m}$ and $+21.5 \%$ per $\mathrm{m}$ ).

Total mass of the caecum tissue $(-19.5 \%$ against group vac; $-17.3 \%$ against non-vac/cs-; Table 6) was significantly lower in clinically affected animals. Consequently, the relative body mass per mass of caecum was significantly increased in the presence of clinical signs of an L. intracellularis infection $(+18.2 \%)$ relative to vaccinated animals. Vaccinated animals had the highest ADG $(+13.0 \%)$ in relation to the mass of the stomach. There was a significantly reduced amount of stomach content ( $-32.0 \%$ compared to group vac; $-31.4 \%$ compared to non-vac/cs-) in clinically conspicuous animals.

There were no significant differences between the groups regarding the ratio of the mass of the small intestine and the length of the small intestine. Numerically, the relation was highest for the non-vaccinated, clinically

Table 3 Apparent precaecal digestibility values of organic matter, crude protein and starch in piglets

\begin{tabular}{|c|c|c|c|c|c|c|}
\hline \multirow{3}{*}{$\begin{array}{l}\text { Diet } \\
\text { component }\end{array}$} & \multicolumn{6}{|c|}{ Apparent precaecal digestibility rates (\%) } \\
\hline & \multicolumn{2}{|l|}{ Vac } & \multicolumn{2}{|c|}{ Non-vac/cs- } & \multicolumn{2}{|c|}{ Non-vac/cs+ } \\
\hline & Mean & SD & Mean & SD & Mean & SD \\
\hline Organic matter & 62.2 & 7.94 & 66.7 & 2.03 & 64.7 & 5.09 \\
\hline Crude protein & 71.6 & 5.18 & 72.5 & 3.93 & 70.2 & 4.25 \\
\hline Starch & 91.3 & 2.32 & 93.2 & 1.97 & 93.3 & 2.31 \\
\hline
\end{tabular}

Vac vaccinated with Enterisol Illeitis, Non-vac/cs- not vaccinated, clinically no signs, Non-vac/cs + not vaccinated, clinical signs

Values within a row with different superscripts differ significantly at $P<0.05$

(significances are missing) non-affected animals (in $\mathrm{g} / \mathrm{m}$; non-vac/cs-: $78.1 \pm 6.39$, vac: $74.6 \pm 9.39$, non-vac/cs+: $71.6 \pm 6.98$ ). There were also no significant differences between the mass of the small intestine and the mass of the stomach. Numerically, the mass of the small intestine was lowest in relation to the mass of the stomach in the clinically healthy animals (non-vac /cs-: $4.72 \pm 0.61 ; \quad$ vac: $5.03 \pm 0.55$; non-vac/cs: $5.07 \pm 0.68)$.

\section{Discussion}

Performance losses in the course of an L. intracellularis infection result from lower average daily gains and a feed conversion ratio which is worse [5-8]. The economic losses due to this infection with $L$. intracellularis in pigs are the main issue for the pig industry [1-4].

Table 4 Apparent total tract digestibility of organic matter and nutrients in piglets

\begin{tabular}{|c|c|c|c|c|c|c|}
\hline \multirow{3}{*}{$\begin{array}{l}\text { Diet } \\
\text { component }\end{array}$} & \multicolumn{6}{|c|}{ Apparent total tract digestibility (\%) } \\
\hline & \multicolumn{2}{|l|}{ Vac } & \multicolumn{2}{|c|}{ Non-vac/cs- } & \multicolumn{2}{|c|}{ Non-vac/cs+ } \\
\hline & Mean & SD & Mean & SD & Mean & SD \\
\hline Organic matter & 86.4 & 1.46 & 86.9 & 1.81 & 84.8 & 2.19 \\
\hline Crude fat & 72.1 & 4.08 & 73.1 & 6.15 & 71.5 & 4.31 \\
\hline Crude fibre & 18.8 & 7.64 & 22.9 & 10.2 & 14.4 & 15.3 \\
\hline Crude protein & $83.0^{\mathrm{a}}$ & 1.72 & $83.9^{\mathrm{a}}$ & 2.03 & $80.7^{\mathrm{b}}$ & 2.57 \\
\hline Starch & 98.9 & 0.27 & 99.0 & 0.15 & 98.8 & 0.26 \\
\hline
\end{tabular}

Vac vaccinated with Enterisol Illeitis, Non-vac/cs- not vaccinated, clinically no signs, Non-vac/cs + not vaccinated, clinical signs

a,b Values within a row with different superscripts differ significantly at $P<0.05$ 
Table 5 Morphometric parameters and relations between morphometric parameters as well as relations to performance in piglets

\begin{tabular}{|c|c|c|c|c|c|c|}
\hline \multirow{3}{*}{$\begin{array}{l}\text { Parameter } \\
\text { /Organ }\end{array}$} & \multicolumn{6}{|c|}{ Total value and relations of parameters } \\
\hline & \multicolumn{2}{|l|}{ Vac } & \multicolumn{2}{|c|}{ Non-vac/cs- } & \multicolumn{2}{|c|}{ Non-vac/cs+ } \\
\hline & Mean & SD & Mean & SD & Mean & SD \\
\hline \multicolumn{7}{|l|}{ Length (m) } \\
\hline Nose-rump & 0.89 & 0.03 & 0.90 & 0.03 & 0.90 & 0.05 \\
\hline Small intestine & $15.9^{\mathrm{ab}}$ & 1.57 & $14.6^{\mathrm{b}}$ & 1.12 & $16.2^{\mathrm{a}}$ & 1.37 \\
\hline Caecum & 0.22 & 0.02 & 0.21 & 0.02 & 0.21 & 0.01 \\
\hline Colon & 3.03 & 0.39 & 2.98 & 0.28 & 2.96 & 0.31 \\
\hline
\end{tabular}

Relation body weight to nose rump and organ length $(\mathrm{kg} / \mathrm{m})$

$\begin{array}{lllllll}\text { Nose-rump } & 30.4^{\mathrm{a}} & 1.44 & 29.7^{\mathrm{ab}} & 1.59 & 28.2^{\mathrm{b}} & 2.02 \\ \text { Small intestine } & 1.72^{\mathrm{ab}} & 0.21 & 1.83^{\mathrm{a}} & 0.17 & 1.56^{\mathrm{b}} & 0.12 \\ \text { Caecum } & 123 & 7.83 & 126 & 18.9 & 123 & 11.3 \\ \text { Colon } & 8.98 & 0.95 & 9.03 & 1.11 & 8.60 & 1.03\end{array}$

Relation ADG to nose rump and organ length $(\mathrm{g} / \mathrm{m})$

$\begin{array}{lllllll}\text { Nose-rump } & 1010^{\mathrm{a}} & 78.6 & 953^{\mathrm{ab}} & 71.7 & 875^{\mathrm{b}} & 128 \\ \text { Small intestine } & 57.1^{\mathrm{a}} & 9.44 & 58.7^{\mathrm{a}} & 6.57 & 48.3^{\mathrm{b}} & 6.85 \\ \text { Caecum } & 4070 & 300 & 4056 & 635 & 3808 & 622 \\ \text { Colon } & 299 & 45.9 & 289 & 35.1 & 267 & 48.7\end{array}$

Vac vaccinated with Enterisol ${ }^{\oplus}$ lleitis, Non-vac/cs- not vaccinated, clinically no signs, Non-vac/cs + not vaccinated, clinical signs

${ }^{a}, \mathrm{~b}$ Values within a row with different superscripts differ significantly at $P<0.05$

Table 6 Organ mass and relation of body weight and average daily gains to mass of organs

\begin{tabular}{|c|c|c|c|c|c|c|}
\hline \multirow{3}{*}{$\begin{array}{l}\text { Parameter / } \\
\text { Organ }\end{array}$} & \multicolumn{6}{|c|}{ Total value and relations of parameters } \\
\hline & \multicolumn{2}{|l|}{ Vac } & \multicolumn{2}{|c|}{ Non-vac/cs- } & \multicolumn{2}{|c|}{ Non-vac/cs+ } \\
\hline & Mean & SD & Mean & SD & Mean & SD \\
\hline \multicolumn{7}{|l|}{ Mass (g) } \\
\hline Stomach & 236 & 31.2 & 243 & 22.6 & 230 & 22.1 \\
\hline Small intestine & 1173 & 82.7 & 1142 & 124 & 1165 & 173 \\
\hline Caecum & $74.8^{\mathrm{a}}$ & 8.94 & $72.8^{\mathrm{a}}$ & 14.6 & $60.2^{b}$ & 9.41 \\
\hline Colon & 418 & 78.9 & 439 & 57.8 & 400 & 58.0 \\
\hline \multicolumn{7}{|c|}{ Relation body weight to organ mass $(\mathrm{g} / \mathrm{g})$} \\
\hline Stomach & 115 & 10.6 & 110 & 7.40 & 110 & 7.46 \\
\hline Small intestine & 23.1 & 1.95 & 23.5 & 2.60 & 22.0 & 2.72 \\
\hline Caecum & $363^{b}$ & 32.2 & $376^{\mathrm{ab}}$ & 54.0 & $429^{a}$ & 71.6 \\
\hline Colon & 66.3 & 11.6 & 61.3 & 4.65 & 64.2 & 9.48 \\
\hline \multicolumn{7}{|c|}{ Relation ADG to organ mass $(\mathrm{g} / \mathrm{g})$} \\
\hline Stomach & $3.83^{\mathrm{a}}$ & 0.48 & $3.53^{\mathrm{ab}}$ & 0.31 & $3.39^{\mathrm{b}}$ & 0.34 \\
\hline Small intestine & 0.76 & 0.06 & 0.75 & 0.09 & 0.68 & 0.12 \\
\hline Caecum & 12.0 & 1.00 & 12.0 & 1.67 & 13.3 & 3.15 \\
\hline Colon & 2.22 & 0.50 & 1.96 & 0.17 & 1.99 & 0.43 \\
\hline
\end{tabular}

Vac vaccinated with Enterisol ${ }^{\oplus}$ leitis, Non-vac/cs- not vaccinated, clinically no signs, Non-vac/cs + not vaccinated, clinical signs

${ }^{a, b}$ Values within a row with different superscripts differ significantly at $P<0.05$

\section{Effects on performance}

A high feed intake is the basic prerequisite for exploiting the performance potential of pigs [30,31]. The first consequence of an infection is the reduced appetite and therefore lower feed intake [32]. In the present study, feed intake in the group non-vac/cs+ was only numerically reduced by $10.2 \%$ and in group non-vac/cs- by $6.94 \%$ compared to the feed intake of vaccinated animals. In the literature, there is up to now no direct comparison between these three types of groups. In a study with an experimental $L$. intracellularis infection, a reduced feed intake was observed in animals aged 28 to 49 days. When groups with different inoculation doses (counts per pig) were compared $\left(7.2 \times 10^{7}\right.$ to $3.8 \times 10^{5}$ and $7.2 \times 10^{7}$ to $2.2 \times 10^{6}$ ), the reduction in feed intake was $1.27 \%$ and $7.85 \%$, respectively [33]. In another study the reduction in feed intake was $3.79 \%$ in pigs at 38 to 58 days of age after experimental infection $\left(1.26 \times 10^{10} \mathrm{~L}\right.$. intracellularis organisms in the inoculum) in comparison with animals treated with $50 \mathrm{ppm}$ tylvalosin for 14 further days after experimental infection [34]. For viral intestinal infections (porcine epidemic diarrhoea $=\mathrm{PED}$ ), there are also significant effects on performance. After a 4-day acclimatisation period, the infection with PED resulted in a reduced feed intake of $11.5 \%$ over a period of 21 days [22]. In a recent meta-analysis on the effects of infections on feed intake due to bacterial infections of the digestive system (mainly E. coli in piglets) the reduction was $15 \%$ [19]. In conclusion, an infection with $L$. intracellularis in the acute phase seems to have a somewhat lower effect on the feed intake than viral or classical bacterial intestinal infection in piglet rearing. In the present study, the effects of an L. intracellularis infection on the feed intake were higher in percentage terms than in the literature $[8,34]$. This can be interpreted as the effect of strict division of animals into three groups according to clinical appearance and vaccination status. At the same time, it should be borne in mind that the experimental approach here per se may reflect the natural conditions in the field best because naturally - infected, conspicuous animals have been selected. Experiments with an artificial infection are not possible in the classical sense due to the lack of possibility of cultural cultivation. For that reason usually strains of $L$. intracellularis are freshly harvested from McCoy cells [35-37]. On the other hand, digestibility studies in animals with a natural microbiome for an $L$. intracellularis infection may simulate the conditions in the field better. This is because interactions between the natural composition of the microbiome in pigs and nutrient digestibility are proven [38]. This is the reason why in the present study unlike in conventional studies with experimental infection, animals from a farm with an early field infection were used. 


\section{Growth factor and inflammation}

The Insulin-like growth factor I is an important anabolic hormone that mediates growth and development of individuals [39]. IGF-1 is probably also a useful biomarker of growth performance for comparing pigs from the same herd [40]. In the present study no significant differences in the serum levels of IGF-1 were found. In general, it is stated that the variation in hepatic IGF-1 expression is probably due to the natural variability observed in the young growing pigs. Therefore, this might have an influence on the statistically significant gained results [40].

Numerically, the vaccinated animals had the highest mean values (285 ng / mL). Non-vaccinated, clinically healthy animals $(-4.72 \%)$ and pigs with clinical signs of infection $(-20.9 \%)$ had lower IGF-1 concentrations in the serum at the time of dissection.

From literature it is known that pigs with higher post-weaning average daily gains have significantly increased odds of elevated IGF-1 expression in the liver [39]. For example in the named study, the pig with the highest average daily gain (556 g/day) was 1073 (95\% CI: 16.02$71,892)$ times more likely to have higher IGF-1 expression than the pig with the lowest gain $(140 \mathrm{~g} /$ day; $P<0.01)$ [39].

In a five-week feeding experiment with piglets on the effects of antibiotics (22.7 ppm of chlortetracycline, $22.7 \mathrm{ppm}$ of sulfamethazine, and $11.4 \mathrm{ppm}$ of penicillin) the levels of IGF-1 in untreated animals were significant lower $(-19.2 \%$; 105 vs. $131 \mathrm{ng} / \mathrm{mL} p<0.001$; [41]). This observation was accompanied by a decrease in average daily gains of $20.6 \%(p<0.01$; [41]). From studies on growing pigs, it has been known for a long time that restrictive feeding is associated with lower IGF-1 levels in the serum [42]. In general, this is in accordance with the results found here with a lower feed intake in clinically conspicuous animals. Therefore, higher IGF-1 concentrations may be the explanation for the numerically higher feed consumption and the increased average daily gains in the vaccinated group.

\section{Nutrient digestibility and morphometry of organs}

One of the characteristics of an infection with the pathogen $L$. intracellularis in pigs is a downregulation of various genes in the enterocytes. These play an important role in the mechanisms of nutrient absorption [21]. Therefore, it can be assumed that an infection with $L$. intracellularis can have an influence on the digestibility of nutrients. No significant differences were found in the study with regard to the precaecal digestibility of the nutrients, although numerically the digestibility rate of nitrogen decreased by $2.3 \%$ percentage points in the presence of clinical manifestations of the disease (non$\mathrm{vac} / \mathrm{cs}+\mathrm{vs}$. non-vac/cs-). Until now, there is no comparative study dealing with the influence of this relevant infectious agent of the pig on digestibility of nutrients
[22]. For porcine reproductive and respiratory syndrome virus, porcine epidemic diarrhoea virus and a co-infection from both illnesses no significant influence on the ileal digestibility was seen [22]. This is consistent with results found here.

The response of the gastrointestinal tract to ingested nutrients is a complex and closely controlled process [24]. A leading mechanism of intestinal adaptation to enteral availability nutrients is driven by humoral factors like the intestinotrophic peptide glucagon-like peptide-2 (GLP-2) [25]. Enteroendocrine L-cells secrete GLP-2 after direct stimulation by nutrients present in the ileal digesta [25]. GLP-2 is responsible for the adjustment control of the intestinal absorption area and nutrient availability [43]. Within a few days massive adjustments are possible [43]. For example, a reduction in the mass of the small intestine in rats within 6 days could be detected in $34 \%$ of cases with parenteral nutrition [43]. Therefore, low digestibility rates of nutrients in the small intestine cause the intestine to react with a morphometric adjustment in the form of growth. This could be the explanation for the fact that a disease might not directly influence the precaecal digestibility of nutrients. However, the result of this adaptation is a longer intestine or higher relative intestinal mass or both. Thus, the relative efficiency of the digestive organs per se might be reduced. Indications for such organ adaptations could also be found in this study. Relative to the length of the small intestine, the clinically conspicuous animals had the smallest body mass and relative to the organ mass of the small intestine, they had, numerically, the smallest body mass. In relation to the organ length, the group of clinically conspicuous animals had significantly lower average daily weight gains.

In the present study, it was seen that average total tract digestibility of nitrogen was significantly reduced in clinically affected animals. This was also demonstrated in the above-mentioned study for the combined infection of PRRSV and PED [22]. The total digestibility of the dry matter, nitrogen and the gross energy was also reduced [22]. While in the aforementioned study the reduction in nitrogen digestibility was $12.8 \%$ [22], it was only $3.81 \%$ for the clinically conspicuous animals in the present study.

It can be presumed that mucosal alterations might lead to increased presence of nitrogen compounds in the intestine as hypothesised for Brachyspira infection in swine [44]. This might be due to the increased amounts of endogenous nitrogen in the distal parts of the small intestine and parts of the large intestine. It is known that L. intracellularis is also a prevalent cause of naturally acquired colitis in pigs. About $25 \%$ of endogenous nitrogen originates from the large intestine while $59.9 \%$ originates from the small intestine [45]. The reabsorption of endogenous 
nitrogen (total $10.7 \mathrm{~g}$ ) amounted to $79 \%$ towards the end of the small intestine and $88 \%$ for the whole digestive tract [46] for an nitrogen-intake of $23.6 \mathrm{~g} /$ day. Other authors calculated for higher endogenous secretion (18.1 g for $40 \mathrm{~g}$ nitrogen-intake a day [47] and $16.1 \mathrm{~g}$ for $35 \mathrm{~g}$ nitrogen-intake [48] with reabsorption up to the end of the digestive tract from $90 \%$ or rather $78 \%$ ). Therefore a lower reabsorption of endogenous nitrogen could be a reason for a lower digestibility of nitrogen in clinically apparent piglets.

\section{Conclusion}

This study clearly shows that the performance of pigs is adversely affected by an $L$. intracellularis infection. The lower average weight gain is primarily caused by a lower feed intake. The precaecal digestibility of the nutrients was not reduced significantly. Adaptation mechanisms lead to increased length and relative mass of the small intestine in diseased animals. Therefore, the relative efficiency of nutrient utilisation might be adversely affected. In the case of vaccinated animals, the lowest effects of an $L$. intracellularis infection were observed concerning the performance of the animals.

\begin{abstract}
Abbreviations
ADFI: Average daily feed intake; ADG: Average daily gains; ATTD: Apparent total tract digestibility; DK: Danish Landrace 50\% x Yorkshire 50\%; DM: Dry matter; FCR: Feed conversion ratio; GLP-2: Glucagon-like peptide-2; IGF1: Insulin-like growth factor 1; ME: Metabolizable Energy; Non-vac/cs-: Not vaccinated, clinically no signs; Non-vac/cs + : Not vaccinated, clinical signs; PRRSV: Porcine Reproductive and Respiratory Syndrome Virus; PED: Porcine epidemic diarrhoea; ST: Salmonella typhimurium; Vac : vaccinated with Enterisol ${ }^{\circ}$ leitis
\end{abstract}

\section{Acknowledgements}

We would like to thank the farmer who provided the animals from his stock for these studies and Frances Sherwood-Brock for editing the manuscript to ensure correct English.

\section{Funding}

The study was financially supported by Boehringer Ingelheim Vetmedica GmbH, D-55216 Ingelheim am Rhein, Germany. The role of the funding body was merely financial for purchasing the materials and the analysis of the data for the trials at the Institute for Animal Nutrition, University of Veterinary Medicine Hanover, Foundation. They did not have any role in the collection, interpretation, analysis and writing of the data.

\section{Availability of data and materials}

The datasets used and/or analysed during the current study are available from the corresponding author on reasonable request.

\section{Authors' contributions}

$\mathrm{CV}$ and JK were the initiators of the idea. CV and JK designed the study. KR was responsible for designing the study in statistical terms. E-UP, IVdB, CV and $\mathrm{JM}$ visited the farm, selected the animals and were responsible for clinical investigations as well as for taking the samples. Investigations and analyses at the university were made by JM, CV and SS. MS performed the analysis of IGF-1. JM, CV and KR did the statistics. CV wrote the paper. All authors critically revised the manuscript and approved the final version of the manuscript. All authors agreed to be accountable for all aspects of the work.

\section{Ethics approval and consent to participate}

The animals were killed according to $\S 4$, paragraph 3 of the Animal Protection Act, exclusively to use their organs or tissues for scientific purposes ("Tötungsanzeige beim Tierschutzbeauftragten der Stiftung Tierärztliche Hochschule Hannover vom 16.07.2012"). The animals had to be brought to the university, since the killing of the animals for organ removal may not take place on the farm legally. The animals came from a farm where animals excreted Lawsonia intracellularis with their faeces in consequence of a natural infection. Some of the animals had already been immunized against Lawsonia intracellularis with a commercially available vaccine at the time of removal according to the farmer's decision. All animals were healthy at the time of removal, differing only in faecal consistency. The animals showed no diarrhea. The animals came from different boxes. The removal of organs for scientific purposes can only be justified if the collection of samples also reflects natural conditions of digestive physiology, i.e. the feed intake must be undisturbed for several days. Experience has shown that stabling at least two previously unknown animals together to form a group would have meant an additional adaptation phase lasting several days in which the animals would have to get used to each other and form a hierarchy and, therefore, an undisturbed feed intake would have been achieved. This would have been associated with considerable and prolonged stress for the animals. Also, in Germany, the legal requirements ( $\S 28$ Paragraph 1 Sentence 2 of the Animal Welfare Animal Husbandry Ordinance "Tierschutz-Nutztierhaltungsverordnung") make it mandatory to avoid regrouping as far as possible. Economic efficiency, labour and cost savings are no justification for this. Should a regrouping nevertheless become necessary, sufficient alternative, retreat and covering possibilities for inferior animals must be created (Annex I Chap. 2 D Nr. 2 S. 3 $\mathrm{RL}$ 2008/120/EG). The legal requirements show that legislation at national and EU level assumes or has recognised that the stress associated with regrouping the pig is a significant impairment of welfare, which can only be justified on reasonable grounds. Against the background of the short keeping period of only a few days until killing, the considerable strain on the animals due to regrouping would not have been justifiable from the point of view of animal welfare. The boxes were designed in such a way that there was no social isolation, as the pigs had visual, auditory and olfactory contact with each other and the possibility of physical contact existed at any time. Therefore, animal experiments were carried out according to German regulations. It was not an animal experiment requiring a notification or an approval according to the Animal Protection Act (§ 7, paragraph 2, sentence 3).

Consent for publication

Not applicable.

\section{Competing interests}

The authors declare that they have no competing interests.

\section{Publisher's Note}

Springer Nature remains neutral with regard to jurisdictional claims in published maps and institutional affiliations.

\section{Author details \\ ${ }^{1}$ Institute for Animal Nutrition, University of Veterinary Medicine Hannover, Foundation, Bischofsholer Damm 15, D-30173 Hannover, Germany. ${ }^{2}$ Clinic for Cattle, University of Veterinary Medicine Hannover, Foundation, Bischofsholer Damm 15, D-30173 Hannover, Germany. ${ }^{3}$ Tierarztpraxis Dr. Peitzmeier, Meente 24, D-32479 Hille, Germany. ${ }^{4}$ Institute for Biometry, Epidemiology and Information Processing, University of Veterinary Medicine Hannover, Foundation, Bünteweg 2, D-30559 Hannover, Germany.}

Received: 27 February 2017 Accepted: 22 October 2018 Published online: 01 November 2018

\section{References}

1. McOrist S, Smith SH, Green LE. Estimate of direct financial losses due to porcine proliferative enteropathy. Vet Rec. 1997;140(22):579-81.

2. Lawson GHK, Gebhart CJ. Proliferative enteropathy. J Comp Pathol. 2000; 122(2-3):77-100.

3. McOrist S. Defining the full costs of endemic porcine proliferative enteropathy. Vet J. 2005;170(1):8-9. 
4. Jacobson M, Fellstrom C, Jensen-Waern M. Porcine proliferative enteropathy: an important disease with questions remaining to be solved. Vet J. 2010; 184(3):264-8.

5. Brandt D, Kaim U, Baumgartner W, Wendt M. Evaluation of Lawsonia intracellularis infection in a group of pigs in a subclinically affected herd from weaning to slaughter. Vet Microbiol. 2010;146(3-4):361-5.

6. Pedersen KS, Skrubel R, Stege H, Angen O, Stahl M, Hjulsager C, Larsen LE, Nielsen JP. Association between average daily gain, faecal dry matter content and concentration of Lawsonia intracellularis in faeces. Acta Vet Scand. 2012:54:58.

7. Johansen M, Nielsen M, Dahl J, Svensmark B, Baekbo P, Kristensen CS, Hjulsager CK, Jensen TK, Stahl M, Larsen LE, et al. Investigation of the association of growth rate in grower-finishing pigs with the quantification of Lawsonia intracellularis and porcine circovirus type 2. Prev Vet Med. 2013; 108(1):63-72.

8. Collins AM, Barchia IM. The critical threshold of Lawsonia intracellularis in pig faeces that causes reduced average daily weight gains in experimentally challenged pigs. Vet Microbiol. 2014;168(2-4):455-8.

9. Veenhuizen $\mathrm{M}$, Elan $\mathrm{T}$, Soensken $\mathrm{N}$ : The potential economic impact of porcine proliferative enteropathy on the US swine industry. In: $15^{\circ}$ Congress IPVS: 1998; 1998: 64

10. Hardge T, Nickoll E, Grunert H, Elbers K, Langbein U, Keller C, Bleier T, Pohlenz J, Ohlinger $\mathrm{V}$, Schroeder B. Prevention of porcine proliferative enteropathy (PPE) by vaccination-efficacy and economics in European farms. Pig J. 2004;54:17-34.

11. Kroll JJ, Roof MB, Hoffman LJ, Dickson JS, Harris DL. Proliferative enteropathy: a global enteric disease of pigs caused by Lawsonia intracellularis. Anim Health Res Rev. 2005;6(2):173-97.

12. Holyoake $P$, Cutler R. Outbreaks of proliferative haemorrhagic enteropathy on two pig farms. Aust Vet J. 1995;72(7):253-6.

13. McOrist S, Gebhart C. Proliferative enteropathy. Diseases of Swine 10th ed Ames. lowa: Blackwell Publishing; 2012. p. 811-20.

14. Elsasser TH, Caperna TJ, Li C-J, Kahl S, Sartin JL. Critical control points in the impact of proinflammatory immune response on growth and metabolism. J Anim Sci. 2008;86:E105-25.

15. Kelley KW, Bluthe RM, Dantzer R, Zhou JH, Shen WH, Johnson RW, Broussard SR. Cytokine-induced sickness behavior. Brain Behav Immun. 2003;17:S112-8.

16. Johnson RW. Immune and endocrine regulation of food intake in sick animals. Domest Anim Endocrinol. 1998;15(5):309-19.

17. Bluthe RM, Kelley KW, Dantzer R. Effects of insulin-like growth factor-I on cytokine-induced sickness behavior in mice. Brain Behav Immun. 2006;20(1): 57-63.

18. Jacobson M, Andersson M, Lindberg R, Fossum C, Jensen-Waern M Microarray and cytokine analyses of field cases of pigs with diarrhoea. Vet Microbiol. 2011;153(3-4):307-14.

19. Pastorelli $H$, van Milgen J, Lovatto P, Montagne L. Meta-analysis of feed intake and growth responses of growing pigs after a sanitary challenge. Animal. 2012;6(6):952-61.

20. Vannucci FA, Gebhart CJ. Recent advances in understanding the pathogenesis of Lawsonia intracellularis infections. Vet Pathol. 2014;51(2): 465-77

21. Vannucci FA, Foster DN, Gebhart CJ. Laser microdissection coupled with RNA-seq analysis of porcine enterocytes infected with an obligate intracellular pathogen (Lawsonia intracellularis). BMC Genomics. 2013;14:421.

22. Schweer WP, Schwartz K, Burrough ER, Yoon KJ, Sparks JC, Gabler NK. The effect of porcine reproductive and respiratory syndrome virus and porcine epidemic diarrhea virus challenge on growing pigs I: growth performance and digestibility. J Anim Sci. 2016;94(2):514-22.

23. Cera KR, Mahan DC, Cross RF, Reinhart GA, Whitmoyer RE. Effect of age, weaning and Postweaning diet on small intestinal growth and Jejunal morphology in young swine. J Anim Sci. 1988;66(2):574-84.

24. Farre R, Tack J. Food and symptom generation in functional gastrointestinal disorders: physiological aspects. Am J Gastroenterol. 2013;108(5):698-706.

25. Tappenden KA. Mechanisms of enteral nutrient-enhanced intestinal adaptation. Gastroenterology. 2006;130(2):S93-9.

26. Ahlfänger $B$. Investigations on influences of an exocrine pancreatic insufficiency on the length and the histological morphology of the small intestine in young pigs. Hannover: University of Veterinary Medicine Hannover, Foundation; 2016.

27. Nathues $H$, Holthaus K, Beilage EG. Quantification of Lawsonia intracellularis in porcine faeces by real-time PCR. J Appl Microbiol. 2009;107(6):2009-16.
28. Naumann C, Bassler R. Methoden der landwirtschaftlichen Forschungs-und Untersuchungsanstalt, Biochemische Untersuchung von Futtermitteln. In: Methodenbuch III (einschließlich der achten Ergänzungen). Darmstadt: VDLUFA; 2012.

29. Holthaus K. Quantitativer Nachweis von Lawsonia intracellularis mittels realtime PCR in Kotproben von Schweinen. Hannover: University of Veterinary medicine Hannover, Foundation; 2008.

30. Rauw WM, Soler J, Tibau J, Reixach J, Raya LG. Feeding time and feeding rate and its relationship with feed intake, feed efficiency, growth rate, and rate of fat deposition in growing Duroc barrows. J Anim Sci. 2006;84(12): 3404-9.

31. Hermesch S, Kanis E, Eissen JJ. Economic weights for feed intake in the growing pig derived from a growth model and an economic model. J Anim Sci. 2003;81(4):895-903.

32. Klasing KC. Negative consequences of immune response: what can be done by nutritionists? Proc Soc Nutr Physiol. 2006;15:17-23.

33. Paradis M, McKay R, Wilson J, Vessie G, Winkelman N, Gebhart C, Dick C. Subclinical ileitis produced by sequential dilutions of Lawsonia intracellularis in a mucosal homogenate challenge model. In: Proceedings of the American Association of Swine Veterinarians Annual Meeting. 2005:189-191.

34. Guedes RMC, Franca SA, Machado GS, Blumer MA, Cruz ECD. Use of tylvalosin-medicated feed to control porcine proliferative enteropathy. Vet Rec. 2009;165(12):342-6.

35. Collins A, Love RJ, Pozo J, Smith SH, McOrist S. Studies on the ex vivo survival of Lawsonia intracellularis. Swine Health Prod. 2000;8(5):211-5.

36. Wattanaphansak S, Gebhart C, Olin M, Deen J. Measurement of the viability of Lawsonia intracellularis. Can J Vet Res. 2005;69(4):265-71.

37. Borewicz KA, Kim HB, Singer RS, Gebhart CJ, Sreevatsan S, Johnson T, Isaacson RE. Changes in the porcine intestinal microbiome in response to infection with Salmonella enterica and Lawsonia intracellularis. PLoS One. 2015;10(10):e0139106.

38. Vigors S, Sweeney T, O'Shea CJ, Kelly AK, O'Doherty JV. Pigs that are divergent in feed efficiency, differ in intestinal enzyme and nutrient transporter gene expression, nutrient digestibility and microbial activity. Animal. 2016;10(11):1848-55.

39. Slifierz MJ, Friendship R, de Lange CFM, Slavic D, Grgic H, Farzan A. Immunomodulatory factors and infectious agents associated with the hepatic gene expression of the IGF system in nursery pigs. Animal. 2014; 8(5):844-51.

40. Slifierz MJ, Friendship R, de Lange CFM, Rudar M, Farzan A. An epidemiological investigation into the association between biomarkers and growth performance in nursery pigs. BMC Vet Res. 2013;9:247.

41. Hathaway MR, Dayton WR, White ME, Henderson TL, Henningson TB. Serum insulin-like growth factor I (IGF-I) concentrations are increased in pigs fed antimicrobials. J Anim Sci. 1996;74(7):1541-7.

42. Therkildsen $M$, Vestergaard $M$, Busk $H$, Jensen MT, Riis B, Karlsson AH, Kristensen L, Ertbjerg P, Oksbjerg N. Compensatory growth in slaughter pigs-in vitro muscle protein turnover at slaughter, circulating IGF-I, performance and carcass quality. Livest Prod Sci. 2004;88(1-2):63-75.

43. Chance W, Foley-Nelson T, Thomas I, Balasubramaniam A. Prevention of parenteral nutrition-induced gut hypoplasia by coinfusion of glucagon-like peptide-2. Am J Physiol-Gastr L. 1997;273(2):G559-63.

44. Skrlep M, Batorek N, Bonneau M, Fazarinc G, Segula B, Candek-Potokar M. Elevated fat skatole levels in immunocastrated, surgically castrated and entire male pigs with acute dysentery. Vet J. 2012;194(3):417-9.

45. Nyachoti CM, deLange CFM, McBride BW, Schulze H. Significance of endogenous gut nitrogen losses in the nutrition of growing pigs: a review. Can J Anim Sci. 1997;77(1):149-63.

46. Souffrant W, Rerat A, Laplace J, Darcy-Vrillon B, Köhler R, Corring T, Gebhardt G, Bernard F, Jähnichen M, Schneider B. Exogenous and endogenous contributions to nitrogen fluxes in the digestive tract of pigs fed a casein diet. III Recycling of endogenous nitrogen. Reprod Nutr Dev. 1993;33(4): 373-82.

47. Low A. Endogenous nitrogen evaluation from absorption studies [digestive absorption of endogenous nitrogen, pigs]. Colloques de I'INRA (France) 1982.

48. Krawielitzki K, Zebrowska T, Schadereit R, Kowalczyk J, Hennig U, Wünsche J, Herrmann U. Determining of nitrogen absorption and nitrogen secretion in different sections of the pig's intestine by digesta exchange between $15 \mathrm{~N}$ labelled and unlabelled animals. Arch Anim Nutr. 1990;40(1-2):25-37. 